Pacific Journal of Mathematic 


\section{ALGEBRAIC STRUCTURE FOR A SET OF NONLINEAR INTEGRAL OPERATIONS}

\section{DAVID LOWELL LOVELADY}

A generalized addition is introduced for a set of generators, and a generalized multiplication is introduced for a set of evolution systems. Then the mapping which takes a generator to the corresponding evolution system becomes an isomorphism. Necessary and sufficient conditions are found for the generalized addition to reduce to addition, and hence, under these conditions, we are able to write a formula for the evolution system generated by the sum of two generators.

Preliminaries. Let $S=[0, \infty)$, and let $(G,+)$ be a complete normed abelian group with norm $N_{1}$. Let $H$ be the set to which $A$ belongs only in case $A$ is a function from $G$ to $G, A[0]=0$, and there is a number $b$ so that $N_{1}[A[p]-A[q]] \leqq b N_{1}[p-q]$ whenever $(p, q)$ is in $G \times G$. If $A$ is in $H$, let $N_{2}[A]$ be the least number $b$ so that $N_{1}[A[p]-A[q]] \leqq b N_{1}[p-q]$ whenever $(p, q)$ is in $G \times G$, and let $N_{3}[A]$ be the least number $b$ so that $N_{1}[A[p]] \leqq b N_{1}[p]$ whenever $p$ is in $G$.

Let $O A^{+}, O M^{+}$, and $\mathscr{E}^{+}$be as in [8]. Let $O A$ be the set to which $V$ belongs only in case $V$ is a function from $S \times S$ to $H$ so that

(i) $V(x, y)+V(y, z)=V(x, z)$ whenever $(x, y, z)$ is in $S \times S \times S$ and $y$ is between $x$ and $z$, and

(ii) there is a member $\alpha$ of $O A^{+}$so that

$$
N_{2}[V(a, b)] \leqq \alpha(a, b)
$$

whenever $(a, b)$ is in $S \times S$. If $\alpha$ and $V$ are related as in (ii), $\alpha$ will be said to dominate $V$.

Let $O M$ be the set to which $W$ belongs only in case $W$ is a function from $S \times S$ to $H$ so that

(i ) $W(x, y) W(y, z)=W(x, z)$ whenever $(x, y, z)$ is in $S \times S \times S$ and $y$ is between $x$ and $z$, where the multiplication is composition, and

(ii) there is a member $\mu$ of $O M^{+}$so that

$$
N_{2}[W(a, b)-I] \leqq \mu(a, b)-1
$$

whenever $(a, b)$ is in $S \times S$, where $I$ in $H$ is given by $I[p]=p$.

The following theorem is due to Mac Nerney [9].

THEOREM 1. There is a bijection $\mathscr{E}$ from $O A$ onto $O M$ so that if $V$ is in $O A$ and $W$ is in $O M$, then (i), (ii), (iii), (iv), and (v) are 
equivalent.

(i) $W=\mathscr{E}[V]$.

(ii) $W(a, b)[p]={ }_{a} \Pi^{b}[I+V][p]$ whenever $(a, b, p)$ is in $S \times S \times G$.

(iii) $V(a, b)[p]={ }_{a} \Sigma^{b}[W-I][p]$ whenever $(a, b, p)$ is in $S \times S \times G$.

(iv) There is $(\alpha, \mu)$ in $\mathscr{E}^{+}$so that

$$
N_{3}[W(a, b)-I-V(a, b)] \leqq \mu(a, b)-1-\alpha(a, b)
$$

whenever $(a, b)$ is in $S \times S$.

(v) If $(a, p)$ is in $S \times G$, and $h$ is given by $h(t)=W(t, a)[p]$, then $h$ has bounded $N_{1}$-variation on each bounded interval of $S$, and is the only such function such that

$$
h(t)=p+(R) \int_{t}^{a} V[h]
$$

whenever $t$ is in $S$.

REMARK 1. The notions of $\Pi, \Sigma$, and $(R) \int$ are to be taken as in [9].

Let $O A I$ be that subset of $O A$ to which $V$ belongs only in case each of $I+V\left(t, t^{+}\right), I+V\left(t, t^{-}\right), I+V\left(t^{+}, t\right)$, and $I+V\left(t^{-}, t\right)$ has inverse in $H$ whenever $t$ is in $S$. The following theorem is due to Herod [6] (see also [4] and [5]).

Theorem 2. Let $(V, W)$ be in $\mathscr{E}$. Then (i) and (ii) are equivalent.

(i) $V$ is in $O A I$.

(ii) Each value of $W$ has inverse in $H$.

Furthermore, there is a bijection $\mathscr{G}$ from $O A I$ onto OAI such that if $V$ is in OAI, then each of (iii), (iv), (v), and (vi) is true.

(iii) $\mathscr{G}[\mathscr{G}[V]]=V$.

(iv) $\mathscr{G}[V](a, b)=-V(b, a)$ for each $(a, b)$ in $S \times S$ only in case ${ }_{a} \Sigma^{b} N_{3}[V[I-V]-V]=0$ whenever $(a, b)$ is in $S \times S$.

(v) $\mathscr{E}[\mathscr{G}[V]](a, b) \cdot \mathscr{E}[V](b, a)=\mathscr{E}[V](b, a) \cdot \mathscr{E}[\mathscr{G}[V]](a, b)=I$ whenever $(a, b)$ is in $S \times S$.

(vi) $\mathscr{G}[V](a, b)[p]=-{ }_{b} \Sigma^{a} V[I+V]^{-1}[p]$ whenever $(a, b, p)$ is in $S \times S \times G$.

\section{The $\oplus$ Operation.}

Lemma 1. If each of $\alpha$ and $\beta$ is in $O A^{+}$, and $(a, b)$ is in $S \times S$, then ${ }_{a} \Sigma^{b} \alpha[1+\beta]$ exists and is the greatest lower bound of the set to which $r$ belongs only in case there is a chain $\left(t_{k}\right)_{k=0}^{n}$ from a to $b$ so that $r=\sum_{k=1}^{n} \alpha\left(t_{k-1}, t_{k}\right)\left[1+\beta\left(t_{k-1}, t_{k}\right)\right]$. 
Proof. It suffices to show that if $(a, b, c)$ is in $S \times S \times S$, and $b$ is between $a$ and $c$, then

$$
\alpha(a, c)[1+\beta(a, c)] \geqq \alpha(a, b)[1+\beta(a, b)]+\alpha(b, c)[1+\beta(b, c)] .
$$

But $\alpha(a, c) \geqq \alpha(a, b)$ and $\alpha(a, c) \geqq \alpha(b, c)$, so

$$
\begin{aligned}
\alpha(a, c) \beta(a, c) & =\alpha(a, c) \beta(a, b)+\alpha(a, c) \beta(b, c) \\
& \geqq \alpha(a, b) \beta(a, b)+\alpha(b, c) \beta(b, c),
\end{aligned}
$$

and the proof is complete.

THEOREM 3. If each of $V_{1}$ and $V_{2}$ is in $O A$, and $(a, b, p)$ is in $S \times S \times G$, then ${ }_{a} \Sigma^{b} V_{1}\left[I+V_{2}\right][p]$ exists. If, for $i=1,2, \alpha_{i}$ in $O A^{+}$ dominates $V_{i}$, then

$$
\begin{aligned}
& N_{3}\left[V_{1}(a, b)\left[I+V_{2}(a, b)\right]-{ }_{a} \Sigma^{b} V_{1}\left[I+V_{2}\right]\right] \\
& \leqq \alpha_{1}(a, b)\left[1+\alpha_{2}(a, b]-{ }_{a} \Sigma^{b} \alpha_{1}\left[1+\alpha_{2}\right]\right.
\end{aligned}
$$

whenever $(a, b)$ is in $S \times S$. Furthermore, if $U$ is given by $U(a, b)[p]=$ ${ }_{a} \Sigma^{b} V_{1}\left[I+V_{2}\right][p]$, then $U$ is in $O A$.

Proof. Let $(a, b, c, p)$ be in $S \times S \times S \times G$, with $b$ between $a$ and $c$. Now

$$
\begin{aligned}
& N_{1}\left[V_{1}(a, c)\left[I+V_{2}(a, c)\right][p]-V_{1}(a, b)\left[I+V_{2}(a, b)\right][p]\right. \\
&\left.\quad-V_{1}(b, c)\left[I+V_{2}(b, c)\right][p]\right] \\
&=N_{1}\left[V_{1}(a, b)\left[I+V_{2}(a, c)\right][p]-V_{1}(a, b)\left[I+V_{2}(a, b)\right][p]\right. \\
&\left.\quad+V_{1}(b, c)\left[I+V_{2}(a, c)\right][p]-V_{1}(b, c)\left[I+V_{2}(b, c)\right][p]\right] \\
& \leqq {\left[\alpha_{1}(a, b) \alpha_{2}(b, c)+\alpha_{1}(b, c) \alpha_{2}(a, b)\right] N_{1}[p] } \\
&= N_{1}[p]\left(\alpha_{1}(a, c)\left[1+\alpha_{2}(a, c)\right]-\alpha_{1}(a, b)\left[1+\alpha_{2}(a, b)\right]\right. \\
&\left.-\alpha_{1}(b, c)\left[1+\alpha_{2}(b, c)\right]\right) .
\end{aligned}
$$

The theorem is now clear.

Definiton 1. If each of $V_{1}$ and $V_{2}$ is in $O A$, then $V_{1} \oplus V_{2}$ is that member $U$ of $O A$ given by

$$
U(a, b)[p]=V_{2}(a, b)[p]+{ }_{a} \Sigma^{b} V_{1}\left[I+V_{2}\right][p] .
$$

Definition 2. If $V$ is in $O A, V^{*}$ will be that member of $O A$ given by $V^{*}(a, b)=V(b, a)$.

THEOREM 4. If each of $V_{1}, V_{2}$, and $V_{3}$ is in $O A$, then

$$
V_{1} \oplus\left(V_{2} \oplus V_{3}\right)=\left(V_{1} \oplus V_{2}\right) \oplus V_{3} \text {, }
$$


and consequently $(O A, \oplus)$ is a semigroup. $(O A I, \oplus)$ is a subgroup of $(O A, \oplus)$, each subgroup of $(O A, \oplus)$ is contained in $O A I$, and if $V$ is in $O A I$, then

$$
V \oplus \mathscr{G}[V]^{*}=\mathscr{G}[V]^{*} \oplus V=0
$$

Proof. Let $U$ be given by

$$
\begin{aligned}
U(a, b)[p]= & V_{3}(a, b)[p]+{ }_{a} \Sigma^{b} V_{2}\left[I+V_{3}\right][p] \\
& +{ }_{a} \Sigma^{b} V_{1}\left[I+V_{2}\right]\left[I+V_{3}\right][p] .
\end{aligned}
$$

A moment's reflection shows

$$
V_{1} \oplus\left(V_{2} \oplus V_{3}\right)=U=\left(V_{1} \oplus V_{2}\right) \oplus V_{3},
$$

so the first part of the theorem is clear.

Now if $A$ is in $H$, and $I+A$ has inverse in $H$, then

$$
\begin{aligned}
& -A[I+A]^{-1}+A\left[I-A[I+A]^{-1}\right] \\
& \quad=-A[I+A]^{-1}+A[[I+A]-A][I+A]^{-1}=0 .
\end{aligned}
$$

This, with (vi) of Theorem 2, says that if $V$ is in $O A I$, then $V \oplus \mathscr{G}[V]^{*}=0$. Similarly, $\mathscr{C}[V]^{*} \oplus V=0$, so $(O A I, \oplus)$ is a group.

To complete the proof it suffices to show that if $U$ and $V$ are in $O A$, and $U \oplus V=V \oplus U=0$, then $U$ is in $O A I$ and $V=\mathscr{C}[U]^{*}$. If $t$ is in $S$, then [ $U \oplus V]\left(t, t^{+}\right)=0$, so

$$
\begin{aligned}
& U\left(t, t^{+}\right)\left[I+V\left(t, t^{+}\right)\right]+V\left(t, t^{+}\right)=0, \\
& U\left(t, t^{+}\right)\left[I+V\left(t, t^{+}\right)\right]+\left[I+V\left(t, t^{+}\right)\right]=I, \\
& {\left[I+U\left(t, t^{+}\right)\right]\left[I+V\left(t, t^{+}\right)\right]=I .}
\end{aligned}
$$

Similarly, since $[V \oplus U]\left(t, t^{+}\right)=0$, we have

$$
\left[I+V\left(t, t^{+}\right)\right]\left[I+U\left(t, t^{+}\right)\right]=I .
$$

Similar computations for $\left(t, t^{-}\right),\left(t^{+}, t\right)$, and $\left(t^{-}, t\right)$ show that each of $U$ and $V$ is in $O A I$. Also, it is clear that $V$ is given by

$$
V(a, b)[p]=-{ }_{a} \Sigma^{b} U[I+U]^{-1}[p]=\mathscr{G}[U]^{*}(a, b)[p],
$$

so the proof is complete.

Lemma 2. Let each of $\alpha_{1}$ and $\alpha_{2}$ be in $O A^{+}$, and let $\beta$ be a continuous member of $\mathrm{OA}^{+}$. Suppose $\beta(a, b) \leqq{ }_{a} \Sigma^{b} \alpha_{1} \alpha_{2}$ whenever $(a, b)$ is in $S \times S$. Then $\beta=0$.

REMARK 2. Lemma 2 is immediate, and we shall not prove it here. 
Theorem 5. Let each of $V_{1}$ and $V_{2}$ be in $O A$. Then (i) and (ii) are equivalent, and (iii) and (iv) are equivalent.

(i) $V_{1} \oplus V_{2}=V_{1}+V_{2}$.

(ii) $V_{1}\left[I+V_{2}\right]-V_{1}=0$ at all "pairs" of the forms $\left(t, t^{+}\right),\left(t, t^{-}\right)$, $\left(t^{+}, t\right)$, and $\left(t^{-}, t\right)$ for $t$ in $S$.

(iii) $V_{1} \oplus V_{2}=V_{2} \oplus V_{1}$.

(iv) $V_{1}-V_{2}=V_{1}\left[I+V_{2}\right]-V_{2}\left[I+V_{1}\right]$ at all "pairs" of the forms $\left(t, t^{+}\right),\left(t, t^{-}\right),\left(t^{+}, t\right)$, and $\left(t^{-}, t\right)$ for $t$ in $S$.

Proof. We shall indicate the first equivalence, and leave the second to the reader. Since $\left[V_{1} \oplus V_{2}\right]-\left[V_{1}+V_{2}\right]=\Sigma V_{1}\left[I+V_{2}\right]-V_{1}$, it is clear that (i) implies (ii). Now suppose (ii). For $i=1,2$, let $\alpha_{i}$ in $O A^{+}$dominate $V_{i}$. Let $\beta$ in $O A^{+}$be given by $\beta(a, b)=$ ${ }_{a} \Sigma^{b} N_{3}\left[V_{1}\left[I+V_{2}\right]-V_{1}\right]$. Now, by (ii), $\beta$ is continuous, and clearly $\beta(a, b) \leqq{ }_{a} \Sigma^{b} \alpha_{1} \alpha_{2}$ whenever $(a, b)$ is in $S \times S$. Thus $\beta=0$, (i) follows, and the proof is complete.

\section{The $\otimes$ Operation and the Exponential Identity.}

THeOREM 6. Let each of $\left(V_{1}, W_{1}\right)$ and $\left(V_{2}, W_{2}\right)$ be in $\mathscr{F}$, and let $(a, b, p)$ be in $S \times S \times G$. Then each of

$$
{ }_{a} \Pi^{b}\left[I+V_{1}\right]\left[I+V_{2}\right][p] \text { and }{ }_{a} I^{b} W_{1} W_{2}[p]
$$

exists, and they are equal. Furthermore, if $M$ is given by

$$
M(a, b)[p]={ }_{a} \Pi^{b} W_{1} W_{2}[p],
$$

then $M$ is in $O M$.

Proof. Let $U=V_{1} \oplus V_{2}$. Let $\alpha$ be a member of $O A^{+}$which dominates each of $U, V_{1}$, and $V_{2}$, and let $\mu=\mathscr{E}+[\alpha]$. Let $(a, b, p)$ be in $S \times S \times G$, and let $\left(t_{k}\right)_{k=0}^{n}$ be a chain from $a$ to $b$. Now, by [7, Lemma 4],

$$
\begin{aligned}
N_{1}[ & \left.\Pi_{k=1}^{n}\left[I+U\left(t_{k-1}, t_{k}\right)\right][p]-I_{k=1}^{n}\left[I+V_{1}\left(t_{k-1}, t_{k}\right)\right]\left[I+V_{2}\left(t_{k-1}, t_{k}\right)\right][p]\right] \\
\leqq & N_{1}[p] \mu(\alpha, b)^{2} \sum_{k=1}^{n} N_{3}\left[V_{1}\left(t_{k-1}, t_{k}\right)\left[I+V_{2}\left(t_{k-1}, t_{k}\right)\right]\right. \\
& \left.\quad-{ }_{t_{k-1}} \Sigma^{t_{k}} V_{1}\left[I+V_{2}\right]\right] \\
\leqq & N_{1}[p] \mu(\alpha, b)^{2}\left[\sum_{k=1}^{n} \alpha\left(t_{k-1}, t_{k}\right)\left[1+\alpha\left(t_{k-1}, t_{k}\right)\right]-{ }_{a} \Sigma^{b} \alpha[1+\alpha]\right] .
\end{aligned}
$$

It is now clear that ${ }_{a} I^{b}\left[I+V_{1}\right]\left[I+V_{2}\right][p]$ exists and equals ${ }_{a} I^{b}[I+U][p]$ whenever $(a, b, p)$ is in $S \times S \times G$. Now [9, Lemma 1.2] tells us that ${ }_{a} \Pi^{b} W_{1} W_{2}[p]={ }_{a} I^{b}\left[I+V_{1}\right]\left[I+V_{2}\right][p]$ whenever $(a, b, p)$ is in $S \times S \times G$. Since these products describe $\mathscr{E}[U]$, it is clear that $M$ is in $O M$ and the proof is complete. 
Definition 3. If each of $W_{1}$ and $W_{2}$ is in $O M, W_{1} \otimes W_{2}$ is that member $M$ of $O M$ given by $M(a, b)[p]={ }_{a} \Pi^{b} W_{1} W_{2}[p]$.

There emerges from the proof of Theorem 6 a fact which we now record.

THEOREM 7. If each of $V_{1}$ and $V_{2}$ is in $O A$, then

$$
\mathscr{E}\left[V_{1} \oplus V_{2}\right]=\mathscr{E}\left[V_{1}\right] \otimes \mathscr{E}\left[V_{2}\right] .
$$

REMARK 3. Theorem 7, together with the first equivalence of Theorem 5, includes and extends Theorem 6 of [7].

THeOREM 8. Let $V_{1}$ be in $O A, V_{2}$ in $O A I$. Let $U$ in $O A$ be given by

$$
U(a, b)[p]={ }_{a} \Sigma^{b} V_{1}\left[I+V_{2}\right]^{-1}[p] .
$$

Then

$$
\mathscr{E}\left[V_{1}+V_{2}\right]=\mathscr{E}[U] \otimes \mathscr{E}\left[V_{2}\right]
$$

Proof. Let $(a, b, p)$ be in $S \times S \times G$. Now

$$
\begin{aligned}
{\left[\mathscr{E}[U] \otimes \mathscr{E}\left[V_{2}\right]\right](a, b)[p] } & ={ }_{a} \Pi^{b} \mathscr{E}[U] \mathscr{E}\left[V_{2}\right][p] \\
& ={ }_{a} \Pi^{b}[I+U]\left[I+V_{2}\right][p] \\
& ={ }_{a} \Pi^{b}\left[I+V_{1}\left[I+V_{2}\right]^{-1}\right]\left[I+V_{2}\right][p] \\
& ={ }_{a} \Pi^{b}\left[I+V_{1}+V_{2}\right][p] \\
& =\mathscr{E}\left[V_{1}+V_{2}\right](a, b)[p] .
\end{aligned}
$$

This completes the proof.

REMARK 4. Note that by using Theorems 5,7 , and 8 we can compute, under two different sets of hypotheses, $\mathscr{E}\left[V_{1}+V_{2}\right]$ in terms of the $\otimes$ operation.

REMARK 5. The notion of continuously multiplying solutions for generators in order to construct the solution for a sum of generators has been used by Trotter [11] and Chernoff [1], [2] for the case of autonomous linear differential equations with discontinuous linear operators, by Helton [3] for the case of linear Stieltjes integral equations, and by Mermin [10] for the case of autonomous nonlinear differential equations with accretive operators. 


\section{REFERENCES}

1. P. R. Chernoff, Note on product formulas for operator semigroups, J. Functional Analysis, 2 (1968), 238-242.

2. - Semigroup product formulas and addition of unbounded operators, Bull. Amer. Math. Soc., 76 (1970), 395-398.

3. B. W. Helton, Integral equations and product integrals, Pacific J. Math., 16 (1966), 297-322.

4. J. V. Herod, Multiplicative inverses of solutions for Volterra-Stieltjes integral equations, Proc. Amer. Math. Soc., 22 (1969), 650-656.

5. - Coalescence of solutions for nonlinear Volterra equations, Notices Amer. Math. Soc., 16 (1969), 834.

6. Coalescence of solutions for nonlinear Stieltjes equations, J. Reíne Angew. Math., (to appear).

7. D. L. Lovelady, Perturbations of solutions of Stieltjes integral equations, Trans. Amer. Math. Soc., 155 (1971), 175-188.

8. J. S. Mac Nerney, Integral equations and semigroups, Illinois J. Math., 7 (1963), $148-173$.

9. — A nonlinear integral operation, Illinois J. Math., 8 (1964), 621-638.

10. J. L. Mermin, Accretive operators and nonlinear semigroups, Ph. D. Thesis, University of California, Berkeley (1968).

11. H. F. Trotter, On the product of semigroups of operators, Proc. Amer. Math. Soc., 10 (1959), 545-551.

Received June 4, 1970.

Georgia Institute of TeChNology

AND

University of South Carolina 



\section{PACIFIC JOURNAL OF MATHEMATICS}

\section{EDITORS}

\author{
H. SAMElson \\ Stanford University \\ Stanford, California 94305 \\ C. R. HOBBY \\ University of Washington \\ Seattle, Washington 98105
}

J. DugundjI

Department of Mathematics University of Southern California Los Angeles, California 90007

RICHARD ARENS

University of California

Los Angeles, California 90024

\section{ASSOCIATE EDITORS}
E. F. BECKENBACH
B. H. NeUmanN
F. WOLE
K. YOSHIDA

\section{SUPPORTING INSTITUTIONS}

\author{
UNIVERSITY OF BRITISH COLUMBIA \\ CALIFORNIA INSTITUTE OF TECHNOLOGY \\ UNIVERSITY OF CALIFORNIA \\ MONTANA STATE UNIVERSITY \\ UNIVERSITY OF NEVADA \\ NEW MEXICO STATE UNIVERSITY \\ OREGON STATE UNIVERSITY \\ UNIVERSITY OF OREGON \\ OSAKA UNIVERSITY \\ UNIVERSITY OF SOUTHERN CALIFORNIA
}

\author{
STANFORD UNIVERSITY \\ UNIVERSITY OF TOKYO \\ UNIVERSITY OF UTAH \\ WASHINGTON STATE UNIVERSITY \\ UNIVERSITY OF WASHINGTON \\ * * * \\ AMERICAN MATHEMATICAL SOCIETY \\ CHEVRON RESEARCH CORPORATION \\ NAVAL WEAPONS CENTER
}

The Supporting Institutions listed above contribute to the cost of publication of this Journal, but they are not owners or publishers and have no responsibility for its content or policies.

Mathematical papers intended for publication in the Pacific Journal of Mathematics should be in typed form or offset-reproduced, (not dittoed), double spaced with large margins. Underline Greek letters in red, German in green, and script in blue. The first paragraph or two must be capable of being used separately as a synopsis of the entire paper. The editorial "we" must not be used in the synopsis, and items of the bibliography should not be cited there unless absolutely necessary, in which case they must be identified by author and Journal, rather than by item number. Manuscripts, in duplicate if possible, may be sent to any one of the four editors. Please classify according to the scheme of Math. Rev. Index to Vol. 39. All other communications to the editors should be addressed to the managing editor, Richard Arens, University of California, Los Angeles, California, 90024.

50 reprints are provided free for each article; additional copies may be obtained at cost in multiples of 50 .

The Pacific Journal of Mathematics is published monthly. Effective with Volume 16 the price per volume (3 numbers) is $\$ 8.00$; single issues, $\$ 3.00$. Special price for current issues to individual faculty members of supporting institutions and to individual members of the American Mathematical Society: $\$ 4.00$ per volume; single issues $\$ 1.50$. Back numbers are available.

Subscriptions, orders for back numbers, and changes of address should be sent to Pacific Journal of Mathematics, 103 Highland Boulevard, Berkeley, California, 94708.

PUBLISHED BY PACIFIC JOURNAL OF MATHEMATICS, A NON-PROFIT CORPORATION

Printed at Kokusai Bunken Insatsusha (International Academic Printing Co., Ltd.), 7-17, Fujimi 2-chome, Chiyoda-ku, Tokyo, Japan. 


\section{Pacific Journal of Mathematics}

\section{Vol. 37, No. $2 \quad$ February, 1971}

Charles Compton Alexander, Semi-developable spaces and quotient images of metric spaces .................................... 277

Ram Prakash Bambah and Alan C. Woods, On a problem of Danzer. . . . . . . . . 295

John A. Beekman and Ralph A. Kallman, Gaussian Markov expectations and related integral equations . ....................................

Frank Michael Cholewinski and Deborah Tepper Haimo, Inversion of the Hankel

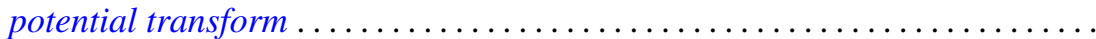

John H. E. Cohn, The diophantine equation

$$
Y(Y+1)(Y+2)(Y+3)=2 X(X+1)(X+2)(X+3) \ldots \ldots \ldots \ldots \ldots
$$

Philip C. Curtis, Jr. and Henrik Stetkaer, A factorization theorem for analytic

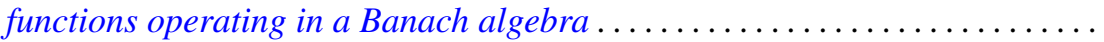

Doyle Otis Cutler and Paul F. Dubois, Generalized final rank for arbitrary limit ordinals

Keith A. Ekblaw, The functions of bounded index as a subspace of a space of entire functions

Dennis Michael Girard, The asymptotic behavior of norms of powers of

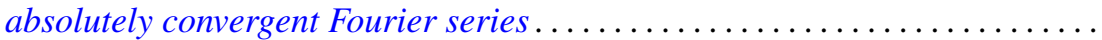

John Gregory, An approximation theory for elliptic quadratic forms on Hilbert spaces: Application to the eigenvalue problem for compact quadratic forms. 383

Paul C. Kainen, Universal coefficient theorems for generalized homology and stable cohomotopy.

Aldo Joram Lazar and James Ronald Retherford, Nuclear spaces, Schauder bases, and Choquet simplexes.

David Lowell Lovelady, Algebraic structure for a set of nonlinear integral operations

John McDonald, Compact convex sets with the equal support property . 429

Forrest Miller, Quasivector topologies

Marion Edward Moore and Arthur Steger, Some results on completability in commutative rings.

A. P. Morse, Taylor's theorem

Richard E. Phillips, Derek J. S. Robinson and James Edward Roseblade, Maximal subgroups and chief factors of certain generalized soluble groups.

Doron Ravdin, On extensions of homeomorphisms to homeomorphisms ...

John William Rosenthal, Relations not determining the structure of $\mathrm{L}$

Prem Lal Sharma, Proximity bases and subbases ........... .

Larry Smith, On ideals in $\Omega_{*}^{u}$. .

Warren R. Wogen, von Neumann algebras generated by operators similar to normal operators

R. Grant Woods, Co-absolutes of remainders of Stone-Čech 